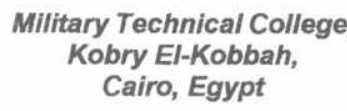

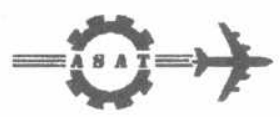

$9^{\text {th }}$ International Conference

On Aerospace Sciences \&

Aviation Technology

\title{
POWER QUALITY ANALYSIS IN A HERCULES AIRCRAFT POWER DISTRIBUTION SYSTEM
}

\author{
J. C. Cartier * D. E. Bouchard** and A. Y. Chikhani **
}

\begin{abstract}
Power system studies can provide useful information on the performance of existing and future systems during both normal and abnormal operating conditions. For example, system studies can reveal harmonics and over-voltage transients, system characteristics which can significantly and adversely affect system performance. The sources of these undesirable characteristics are many and varied, and include transformers, switching transients, nonlinear loads, and devices such as the static power converter. The future use of nonlinear loads is expected to increase since these loads are generally highly efficient. Unfortunately, as the use of these loads increase, waveform distortion is also expected to increase. The resulting waveform distortion will influence overall system performance unless adequate steps are taken to control and maintain power quality.
\end{abstract}

Future advanced aircraft avionics systems will require reliable, redundant, and uninterrupted electrical power to supply flight and mission critical loads. The Canadian Forces CC-130 Hercules aircraft fleet is scheduled for an avionics update that will include complex, sensitive avionics equipment. The power quality required for this update may not be adequate since the existing electrical distribution system was designed to satisfy load requirements of the 1950's.

This paper describes the use of Microtran7 software, a transients analysis simulation program, and the development of a laboratory model to predict the CC-130 Hercules aircraft electrical switching transients and steady-state response, including voltage and current harmonic levels on the power distribution system using tabulated equipment load data. The simulation and laboratory results are then compared for validation with field measurement data.

Keywords: Aircraft power distribution systems, harmonics, transients

* Transport Canada Aircraft Certification, Engineering

** Department of Electrical and Computer Engineering Royal Military College of Canada 


\section{Introduction}

Voltage and current harmonics, can affect the performance and operation of electrical and electronic equipment. The prevailing sources of undesired harmonics and transients are numerous and include transformers, nonlinear power devices such as silicon controlled rectifiers (SCR), nonlinear loads such as static power converters, and switching operations or fault conditions [1]. These harmonics cause additional losses and heating in machines, relay instability, overvoltages due to resonance, instability of controllers, and noise on communication lines [2].

Power quality studies can provide useful about system performance during normal or abnormal operating conditions. This paper describes the use of the Microtran ${ }^{\mathcal{O}}$ transient analysis simulation program and the development of a laboratory model to predict the electrical and harmonic characteristics of the Canadian Forces Hercules aircraft electrical power distribution system. The predicted characteristics are then compared for validation with field measurement data.

\section{System Model}

Aircraft electrical power distribution laboratory and simulation models were developed to represent the physical attributes of the aircraft electrical distribution system. The model

and main electrical distribution channels. The model consists of one constant speed three-phase 40kVA aircraft engine driven generator, three-phase distribution conductors, two 28 VDC, 200 A Transformer Rectifier Units (TRU), circuit breakers (CB) for protection and coordinating the removal and switching on of loads, and lumped distribution system AC and DC loads. The loads are divided into essential and main loads, and are represented as equivalent three-phase and single-phase lumped resistive and inductive components. 


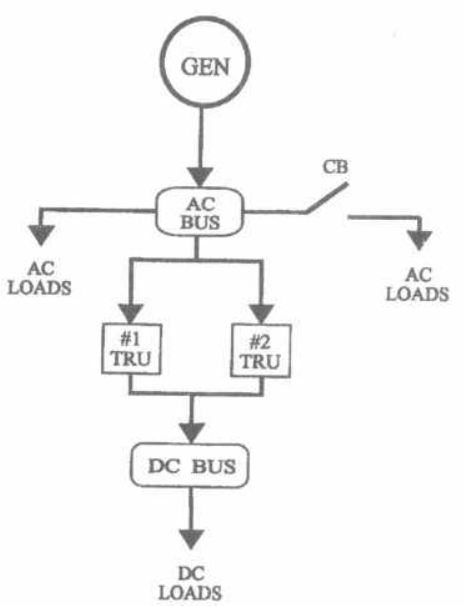

Figure 1 - Single Line Block Diagram of Test Set-Up

Six distinct scenarios as summarized in Table 1 were conducted on the simulation and laboratory models. The test cases were designed to simulate as closely as possible the laboratory model taxi loading profile and test scenarios. Case 1 was designed to examine the effects of the TRUs as a distinct load on the AC bus during a no load condition. During this scenario, AC and DC loads were not applied. Scenarios 2 through 4 were developed to simulate loading conditions on the essential AC and DC bus, whereas scenarios 5 and 6 represented $A C$ and DC loading conditions on the main buses. Case 4 and 6 examined the transient loading effects on the AC and DC bus caused by switching $A C$ loads. The High Frequency (HF) radio and search radar loading characteristics were used to represent the transient loads.

Table 1 AC and DC Load Configuration Summary

\begin{tabular}{|c|c|c|}
\hline Case No. & AC Load & DC Load \\
\hline 1 & No Load & No Load \\
\hline 2 & No Load & Full Load \\
\hline 3 & Full Load & Full Load \\
\hline 4 & Full Load \& HF Radio & Full Load \\
\hline 5 & Full Load & Full Load \\
\hline 6 & Full Load \& Search Radar & Full Load \\
\hline \multicolumn{3}{|c|}{$\begin{array}{l}\text { Note: 1. Case No. 1, 2, } 3 \text { and } 4 \text { represent AC and DC Essential Branch Loads. } \\
\text { 2. Case No. } 5 \text { and } 6 \text { represent AC and DC Main Branch Loads. }\end{array}$} \\
\hline
\end{tabular}




\section{AC and DC Loading}

$A C$ and DC load representations were derived from individual aircraft equipment manufacturer's power consumption data [3]. Inductive and resistive components were used to represent $A C$ loads, and single resistive elements were used to represent DC loads. The tabulation of the aircraft equipment power consumption on the essential and main $A C$ and $D C$ buses during cruise and taxi conditions are shown in Tables 2 and 3 , respectively.

Table 2 - Tabulation of AC Power Consumption

\begin{tabular}{|c|c|c|c|c|c|c|c|}
\cline { 3 - 8 } \multicolumn{2}{c|}{} & \multicolumn{6}{c|}{ Operating Conditions } \\
\cline { 3 - 9 } \begin{tabular}{c}
\cline { 3 - 8 } \\
Source of \\
Power
\end{tabular} & $\Phi$ & S (VA) & PF & Avg (W) & S (VA) & PF & Avg (W) \\
\hline \multirow{3}{*}{ Essential AC Bus } & & & & & & & \\
\cline { 2 - 8 } & B & 9218.48 & 0.76 & 7053.13 & 9465.94 & 0.76 & 7265.63 \\
\cline { 2 - 8 } & C & 1896.25 & 0.71 & 1421.03 & 1994.28 & 0.71 & 1421.03 \\
\hline \multirow{3}{*}{ Main AC Bus } & A & 3630.44 & 0.85 & 3075.27 & 1896.25 & 0.71 & 1357.28 \\
\cline { 2 - 8 } & B & 2232.48 & 0.73 & 1637.01 & 4164.84 & 0.75 & 3106.24 \\
\cline { 2 - 8 } & C & 2232.48 & 0.73 & 1637.01 & 4164.84 & 0.75 & 3106.24 \\
\hline
\end{tabular}

Table 3 - Tabulation of DC Power Consumption

\begin{tabular}{|c|c|c|c|c|}
\cline { 2 - 5 } \multicolumn{1}{c|}{} & \multicolumn{4}{c|}{ Operating Conditions } \\
\cline { 2 - 5 } \multicolumn{1}{c|}{} & \multicolumn{2}{c|}{ Taxi } & \multicolumn{2}{c|}{ Cruise } \\
\hline Source of Power & Avg (A) & Avg (W) & Avg (A) & Avg (W) \\
\hline Essential DC Bus & 182.44 & 5108.52 & 210.53 & 5895.04 \\
\hline Main DC Bus & 163.15 & 4567.80 & 199.09 & 5574.12 \\
\hline
\end{tabular}

\section{MicroTran ${ }^{\circledast}$ Simulation Tool}

MicroTran ${ }^{\otimes}$ is a software program capable of modeling power systems of up to 2000 nodes and 2000 branches. The program aids in developing and analyzing electrical power systems, and has the capability of modeling a wide variety of system components. A MicroTran ${ }^{\star}$ optional add-on program, Harmonic, a Fourier analysis program, was used to analyze the model output binary plot files for harmonic content.

\section{Simulation Model}

The simulation model was used to emulate the laboratory modeled aircraft power distribution system and to explore the performance and accuracy of the model under various controlled loading conditions. The model was designed to replicate one engine generator, three-phase distribution conductors, three-phase essential and main bus 
loads, single-phase and three-phase transient loads, two TRUs, and DC loads to represent the essential and main Bus loading during taxi conditions.

\section{Generator Model}

There are several models, which can be adopted to study three-phase synchronous generator [4-6]. In this case, the Park's equations were used to model the aircraft generator since MicroTran ${ }^{\star}$ can use these variables directly. The mechanical part of the power plant, including rotational speed, was assumed constant. The generator parameters, which are used as input data in the simulation, are depicted in Table 4.

Table 4 - Generator Parameters

\begin{tabular}{|c|l|}
\hline $\begin{array}{c}\text { Machine } \\
\text { Parameters }\end{array}$ & \multicolumn{1}{|c|}{ Description } \\
\hline $\mathrm{R}_{\mathrm{a}}$ (p.u.) & Armature resistance \\
\hline $\mathrm{X}_{1}$ (p.u.) & Arrmature leakage reactance \\
\hline $\mathrm{X}_{\mathrm{d}}$ (p.u.) & Direct axis synchronous reactance \\
\hline $\mathrm{X}_{\mathrm{q}}$ (p.u.) & Quadrature axis synchronous reactance \\
\hline $\mathrm{X}_{\mathrm{d}}^{\prime}$ (p.u.) & Direct axis transient reactance \\
\hline $\mathrm{X}_{\mathrm{d}}^{\prime \prime}$ (p.u.) & Direct axis subtransient reactance \\
\hline $\mathrm{X}_{\mathrm{q}}^{\prime \prime}$ (p.u.) & Quadrature axis subtransient reactance \\
\hline $\mathrm{X}_{\mathrm{o}}$ (p.u.) & Xero sequence reactance \\
\hline $\mathrm{T}_{\mathrm{do}}^{\prime}$ (s) & Direct axis open-circuit transient time constant \\
\hline $\mathrm{T}_{\mathrm{do}}^{\prime \prime}(\mathrm{s})$ & Direct axis open-circuit subtransient time constant \\
\hline $\mathrm{T}_{\mathrm{qo}}^{\prime \prime}(\mathrm{s})$ & Quadrature axis open-circuit transient time constant \\
\hline $\mathrm{i}_{\mathrm{fo}}(\mathrm{A})$ & No load field current \\
\hline
\end{tabular}

\section{7. $A C$ and DC Loads}

The $A C$ and $D C$ electrical system model static loading ernulates existing aggregate loads that are connected to the essential and main distribution channels during aircraft taxi and operating conditions. The $\mathrm{AC}$ and $\mathrm{DC}$ Equipment Power Consumption Charts [3], including equipment manufacturer's data, were used to derive the loads. These charts provide a tabulation of most aircraft equipment average power consumption data during various aircraft operating conditions, and identify equipment loading specifications such as power factor, apparent power per unit (VA), number of units, average watts in operating condition, and source of power derived from the essential or main bus. The AC and DC lumped load component values (inductive and 
resistive) for both the essential and main loads were derived from equations (1) to (4) and the tabulated results from Tables 2 and 3.

Load component elements can be represented as either a series or parallel circuit. The essential and main branch theoretical static load models are depicted in Figures 2 and 3 , respectively. As a parallel circuit, the resistance and inductance values can be found from the following equations:

$$
\begin{gathered}
S_{L}=P_{L}+j Q_{L}=V I^{*}=V^{2} Y_{P}^{*}=\frac{V^{2}}{Z_{S}^{*}} \\
Y_{P}=\frac{S_{L}^{*}}{V^{2}}
\end{gathered}
$$

or

$$
R_{P}=\frac{V^{2}}{P_{L}}=\frac{V^{2}}{\left[S_{L}(P F)\right]}
$$

and

$$
L_{P}=\frac{V^{2}}{\omega Q_{L}}=\frac{V^{2}}{\omega S_{L} \sqrt{1-(P F)^{2}}}
$$

AC Bus

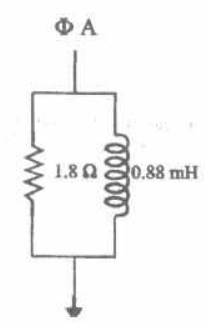

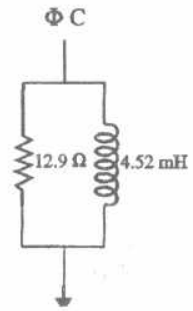

DC Bus

Figure 2 - AC and DC Essential Static Loads 
AC Bus

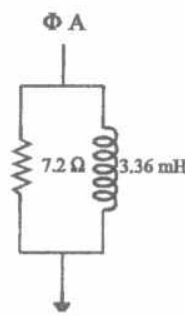

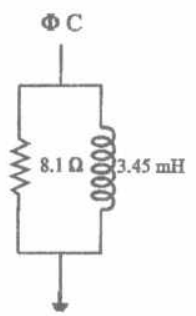

DC Bus
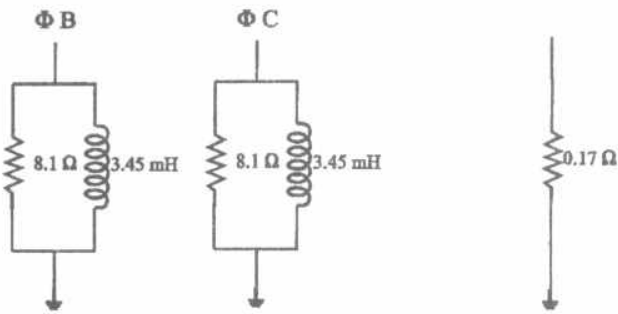

Figure 3 - AC and DC Main Static Loads

\section{Switching Loads}

Two aircraft reactive loads were identified as the optimum choice in studying the transient system response associated with load switching: the search radar and the HF radio. The objective was to identify a single-phase and three-phase load for load switching analysis. The search radar, a single-phase load, was chosen because it consumes a large amount of power (1300 VA at $0.96 \mathrm{PF})$ and the three-phase load, the $\mathrm{HF}$ radio, because it consumes approximately the same amount of power (1111 VA at $0.90 \mathrm{PF}$ ). Figures 4 (a) and (b) depicts the circuit configuration and theoretical component values which were used to represent the search radar and HF radio.

Main AC Bus

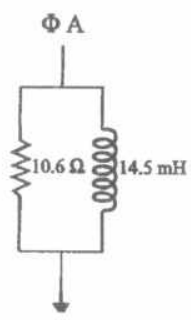

(a) Search Radar

\section{Essential AC Bus}
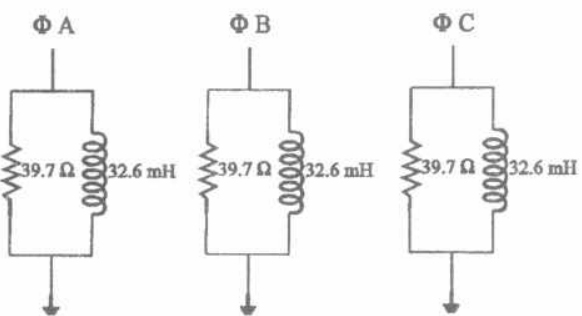

(b) HF Radio

Figure 4- Main and Essential Transient Loads 


\section{Transformer Rectifier Unit}

Static power converters are designed to provide specific power conversion requirements and are available for many different types of applications. The aircraft transformer rectifier units are designed as rectifiers to convert three-phase $115 / 200 \mathrm{VAC}$ at $400 \mathrm{~Hz}$ to a nominal 28 VDC supply for relays, contactors, avionics equipment and battery charging. Due to the primary winding characteristics, ( $\Delta$ and $Y$ configuration), a 30 degree phase shift exists between both secondary voltages. The primary and secondary winding turns ratio are such that both transformers provide the same voltage output magnitudes.

The aircraft TRUs function as twelve-pulse line commutated converters and are designed to supply from 5 to 200 A DC. Thus, the AC supply voltage is used as the commutating voltage and provides either positive or negative bias across the diodes for turn on or turn off. The harmonics produced by line commutated converters are related to the pulse number of the device [2]. For the ideal situation of instantaneous commutation between the conducting elements (diodes in this case), the harmonics which are generated on the AC side of the converter and their magnitudes are given by the following relationships:

$$
\begin{gathered}
h=n \times p \pm 1 \\
I_{h}=\frac{I_{1}}{h}
\end{gathered}
$$

where $h=$ harmonic number, $I_{h}=$ harmonic current magnitude, $n=$ any integer $1,2,3, \ldots$, $p=$ converter pulse number, and $I_{1}=$ fundamental current magnitude.

\section{Laboratory Model}

The laboratory model was developed to verify and validate simulation data. Three different conductor sizes were used to implement the $A C$ and $D C$ power distribution system. The three-phase conductors consisted of three 70 -foot lengths of number 4 AWG (generator feeder cables) and three 25-foot lengths of 12 AWG copper stranded conductors. The number 4 AWG conductors were used to transfer the generator output power to the $\mathrm{AC}$ bus. The number 12 wire gauge conductors were used to provide power from the three-phase AC bus (end of 70 -feet No. 4 AWG conductors) to the input of two parallel-connected $6.3 \mathrm{kVA}$ aircraft TRUs. The 00 AWG conductor was used as a DC distribution line to provide DC power from the TRU output terminais (DC bus) to a $10 \mathrm{~kW}$ DC resistive load. The conductor lengths and gauge are representative of the aircraft installation. The laboratory model and component load values are shown in Figure 5. 


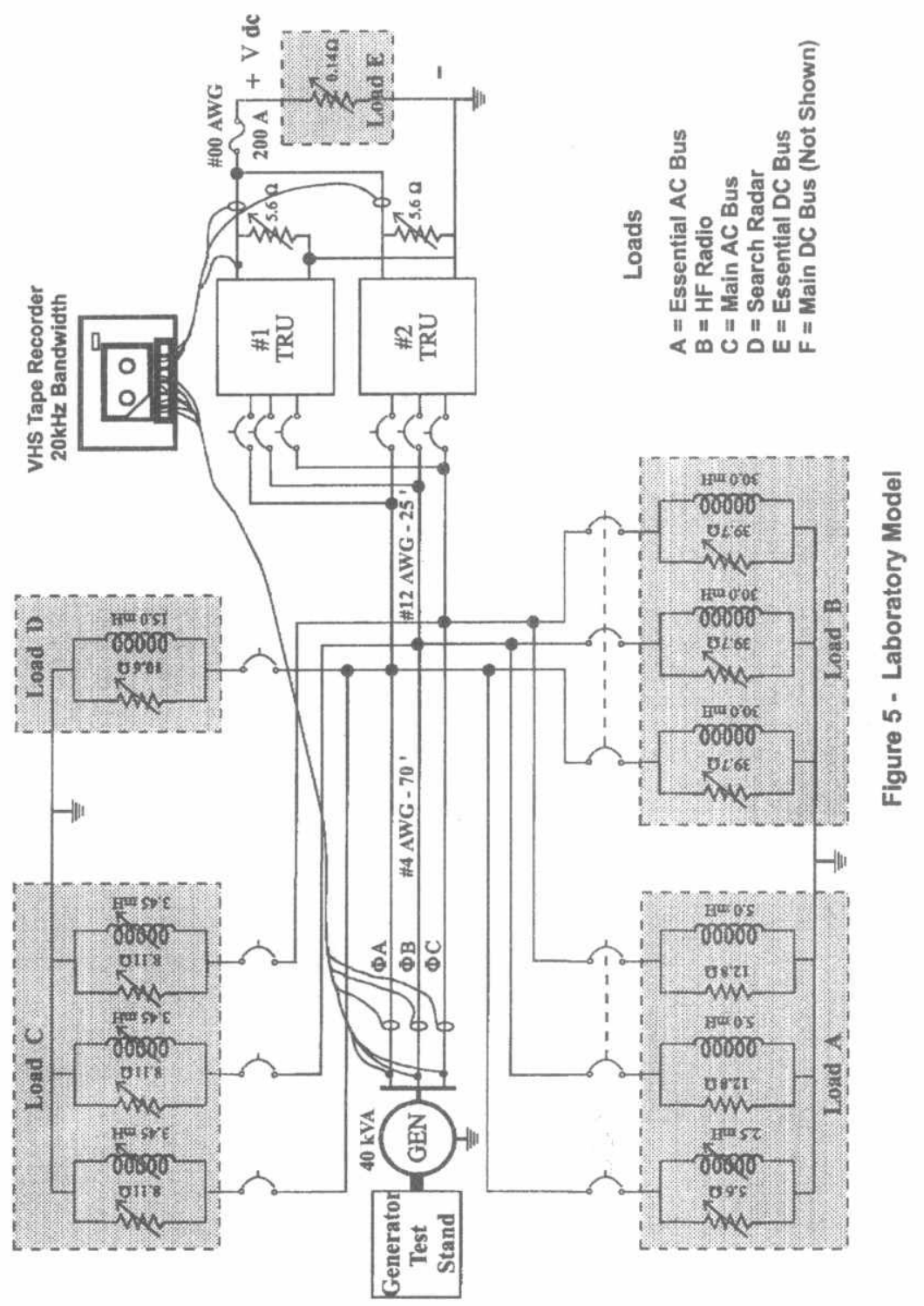




\section{Aircraft Field Data}

Electrical load measurements on the essential and main buses were conducted on a Canadian Forces Hercules aircraft CC-130326E at Canadian Forces Base Trenton, Ontario. The aircraft was secured on a taxiway during load measurements with all four engines operating at $100 \%$ to simulate a taxi condition.

Two VHS $20 \mathrm{kHz}$ bandwidth tape recorders were setup in the aircraft cargo area to record steady-state and transient signals on the essential and main $A C$ and DC buses. One recorder was used to record all signals on the essential $A C$ and $D C$ buses and the other to record electrical signals on the main $\mathrm{AC}$ and DC bus. In addition, a Dranetz analyzer was connected to the essential bus at the distribution panel in the cockpit to monitor and record the three-phase generator output $A C$ bus voltage. The generator output currents were monitored on the main generator feeder cables. The DC bus voltage and currents were monitored at the TRU outputs.

Due to space limitations, only the results for test case 4 and the aircraft data from case 6 will be presented in this paper. The measured data for the aircraft trial, and both the laboratory and simulation models, for test case 4 is summarized in Figures 6 to 14

Figure 6 represents the essential $A C$ bus power loading as a function of phase. The measured loading condition between the simulation, laboratory, and aircraft data for each phase was no greater than $16 \%$. The cruise and taxi tabulated data from Table 2 shows that the theoretical load analysis is conservative.

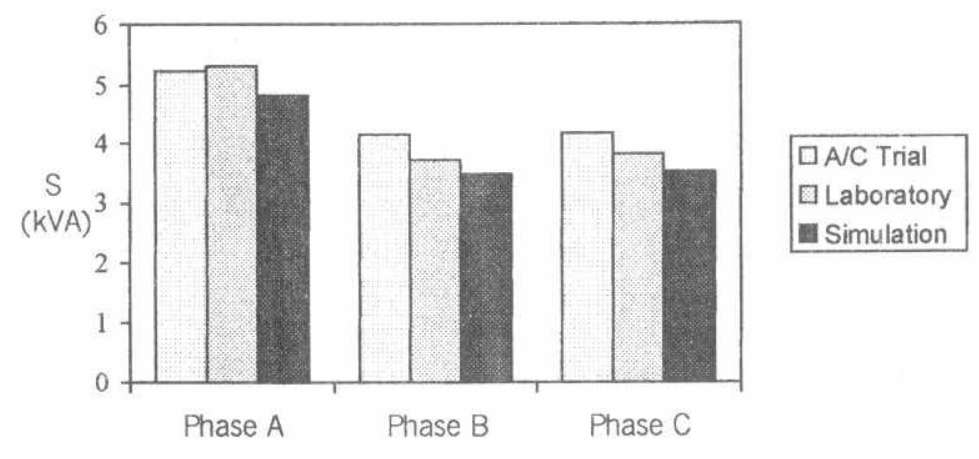

Figure 6 - Essential AC Bus Loading Summary for Test Case No. 4

The essential bus current Total Harmonic Distortion (THD) for the aircraft, laboratory and simulation models for test case 4 is summarized in Figure 7. The increase in THD for the laboratory results for phases $B$ and $C$ can be attributed to unexpected 
perturbations, which occurred on the peaks of the current waveforms. These perturbations were not observed on aircraft data. The developed model values are very close to those observed on the aircraft.

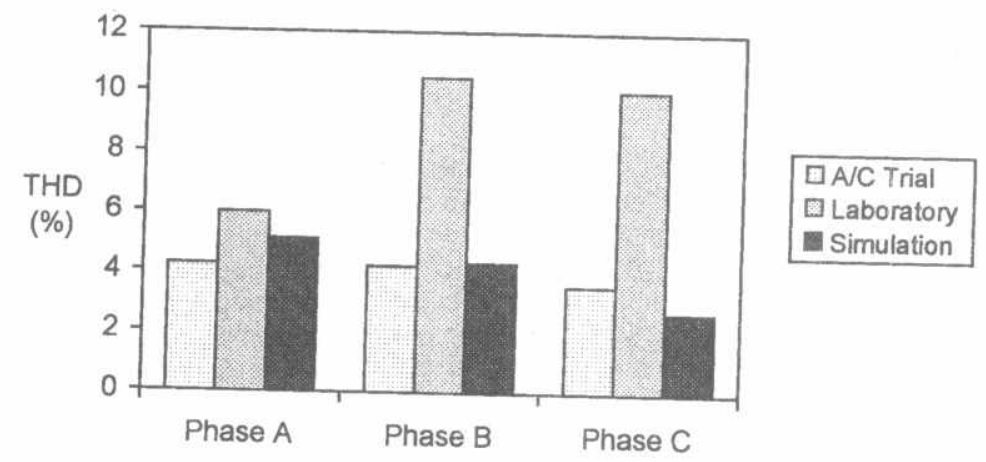

Figure 7 - Essential AC Bus Current THD Summary for Test Case No. 4

While processing the aircraft data, it was discovered that the $A C$ voltage sensors connected on the essential and main buses were inadvertently reversed. Since only data was lost, including used during the recording of individual scenarios, some aircraft Fortunately, theluding PF for all scenarios and $A C$ voltage data for case 5 and 6 . Fortunately, the aircraft AC voltage data for case 1 through 4 was recoverable from the shows the PF, which shows the PF, which was measured, from the laboratory and simulation models, and the tabulated cruise and taxi results. As noted above, the aircraft PF data was lost.

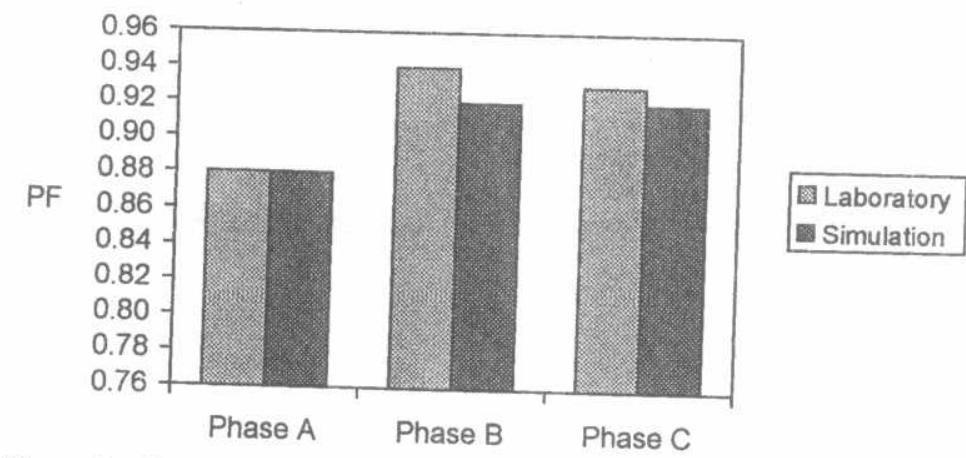

Figure 8 - Essential AC Bus Power Factor Summary for Test Case No. 
Figure 9 shows the simulated phase A voltage and current waveforms during the threephase transient load (HF radio) switch-on event at $0.3 \mathrm{~s}$. Analysis of these waveforms did not show any indication of transients during the switch-on. A similar response was measured from the aircraft data. The voltage magnitude decreased an average of $2.3 \mathrm{~V}$ following the switch-on of the load, and the line current magnitude increased an average of $2.3 \mathrm{~A}$ per phase. Figure 10 represents the corresponding current harmonic profile. As shown, the $11^{\text {th }}$ and $13^{\text {th }}$ harmonics are dominant. Results from phases $B$ and $C$ produced similar waveform characteristics.

Figure 11 shows the phase A current waveform and corresponding transient Fast Fourier Transform (FFT) harmonic plot from the laboratory model during the three-phase load (HF radio) switch-on. The corresponding simulation current harmonic profile was similar, up to and including the $15^{\text {th }}$ harmonic. However, the laboratory voltage waveform, not shown, had a very small distortion on the positive crest of one of the sinusoids. The voltage magnitude before and after the switch-on remained constant. Similar responses occurred for the simulation voltage harmonic profile up to and including the $25^{\text {th }}$ harmonic.

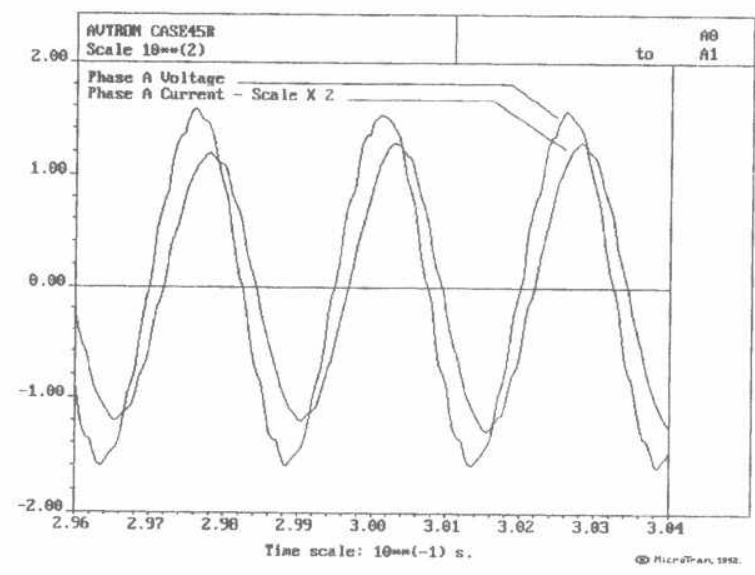

Figure 9-Case 4: Phase $A\left(V_{A} \& I_{A}\right)$ Simulation Waveforms 


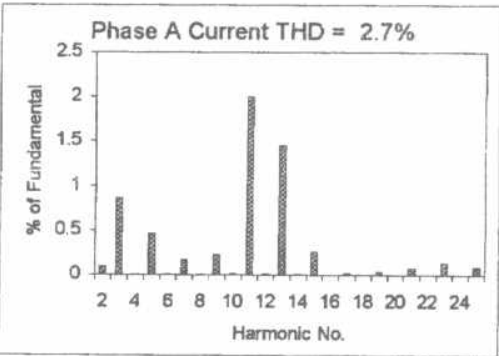

Figure 10 - Case 4: Phase A Simulation IA Harmonic Profile

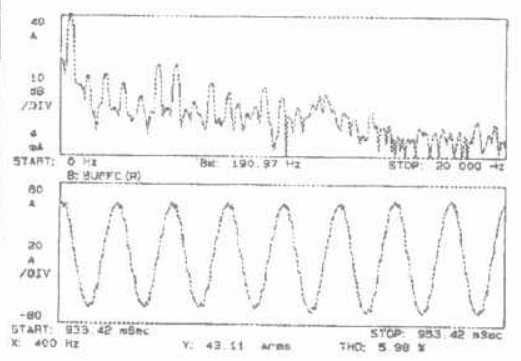

Figure 11 - Case 4: Phase A Laboratory $\mathrm{I}_{\mathrm{A}}$ Waveform \& Harmonic Profile

In Figure 12, the phase $A$ voltage harmonics $\left(11^{\text {th }}, 13^{\text {th }}, 23^{\text {rd }}\right.$, and $\left.25^{\text {th }}\right)$ derived from the simulation and laboratory models were compared with the maximum acceptable harmonic levels as defined in MIL-STD 704E [8]. These maximum harmonic levels (\% of fundamental) were derived from the maximum distortion spectrum of $A C$ voltage plot. This plot quantifies $A C$ voltage distortion in terms of the amplitude of each frequency component. With the exception of the simulation model $11^{\text {th }}$ harmonic, all test Case 4 harmonic levels complied with MIL-STD 704E.

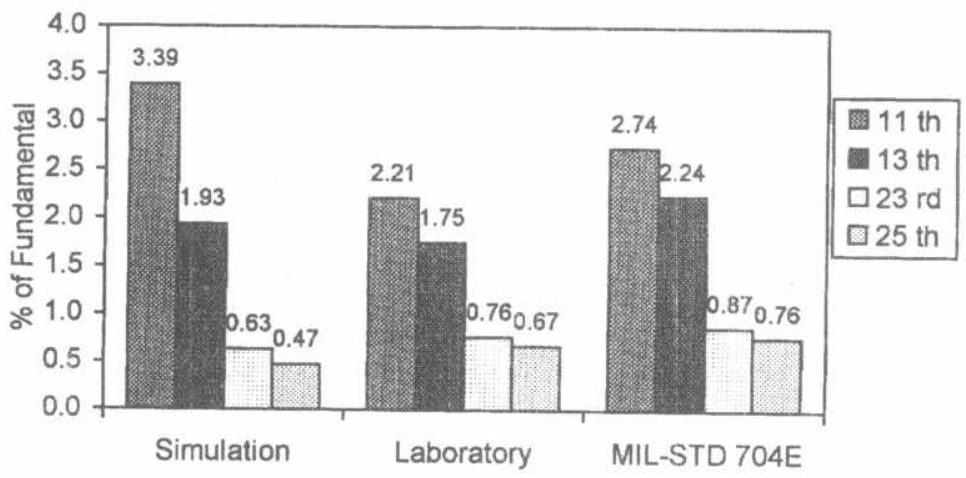

Figure 12 - Phase A Voltage Harmonic Summary for Test Case No. 4 
Figure 13 shows a summary of the $A C$ essential bus unbalance loading profile and the maximum unbalance loading as defined in MIL-STD-704E for case No. 4. As shown, the results from all scenarios exceeded the maximum allowable unbalance limits as defined by MIL-STD-704E

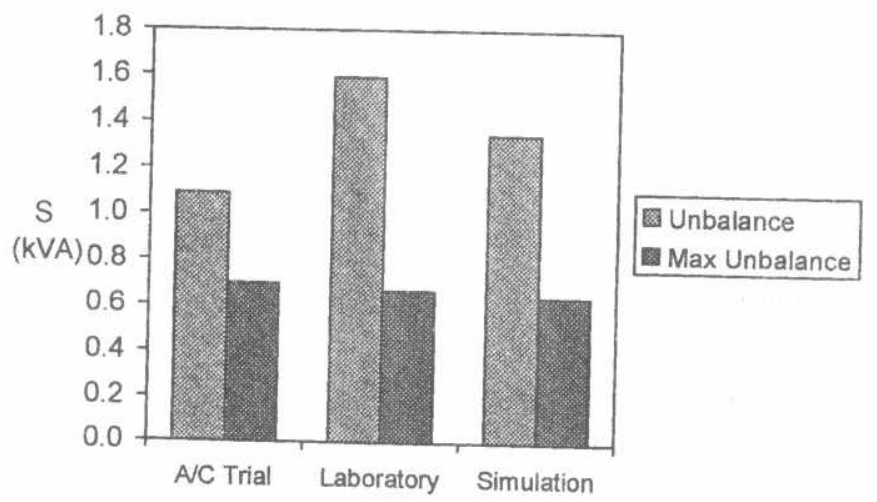

Figure 13 - Essential AC Bus Unbalance Loading Summary for Test Case No. 4

Figure 14 represents the aircraft phase $A$ current waveform during the search radar switch-on event and associated harmonic profile plot. The waveform shows a single cycle surge with a peak amplitude of $29.7 \mathrm{~A}$. A surge of this magnitude does not represent a significant transient. The pre and post switch-on current were measured at $13.5 \mathrm{~A}$ and $21.2 \mathrm{~A}$, respectively. Although the search radar is rated at $1300 \mathrm{VA}$ with a power factor of 0.96 , which represents a steady-state current of $11.3 \mathrm{~A}$, the radar load radar was measured at $7.7 \mathrm{~A}$. This discrepancy is attributable to the fact that the radar was operating in low power mode during the trial. The harmonic profile shows and $13^{\text {th }}$ the same magnitude as the $11^{\text {th }}$ the frequency transient studies. 


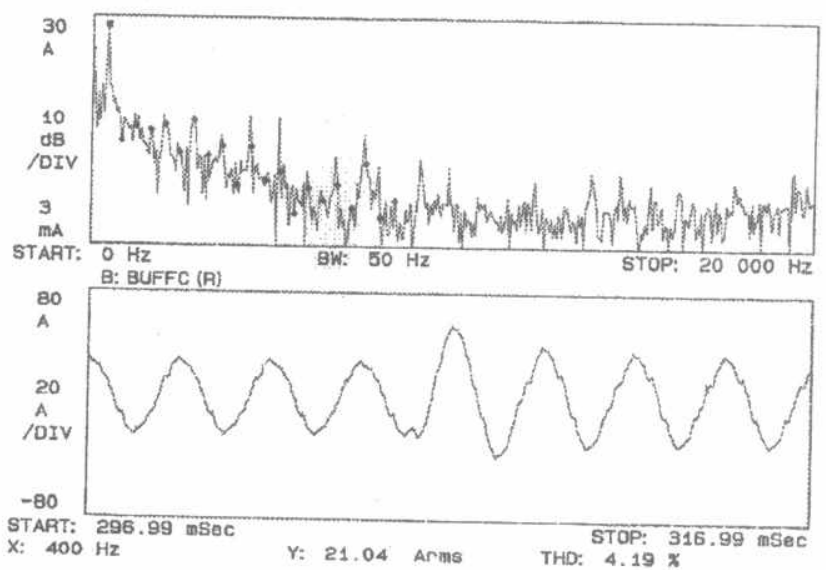

Figure 14 - Case 6: Main AC Bus - $I_{A}$ Waveform \& Harmonic Profile "Aircraft Trial: Search Radar Switch-On"

\section{Conclusion}

Harmonic analysis was performed on both the voltage and current waveforms, which were derived from all six test case scenarios. The results showed that the $11^{\text {th }}$ and $13^{\text {th }}$ harmonics were dominant frequencies for the simulation and laboratory models, and the twelve-pulse commutated converter.

Simulation results showed that the phase voltage, line current, and PF were comparable with results derived from the laboratory model. However, to achieve these results, the simulated generator peak output terminal voltage required incremental adjustments as the $A C$ and $D C$ loads varied. The simulated voltage THD values for all test cases were on average $70 \%$ greater than the laboratory model results and the current THD values were $4 \%$ less. Unfortunately, for the aircraft trial, the voltage data for all three-phases were lost, and as a result, the voltage THD and PF values for the aircraft trial were not
compiled.

The voltage and current load switching transient responses from the simulation and laboratory models, and the aircraft trial did not reveal significant transients. The results from the loading profile showed unbalanced loading conditions, which exceeded the maximum allowable limit as defined by MIL-STD-704E.

As shown in this paper, the MicroTran ${ }^{\otimes}$ simulation program can provide meaningful results, which can be used to accurately predict the performance characteristics of aircraft electrical power distribution systems. 


\section{REFERENCES}

[1] D.D. Ship, "Harmonic Analysis and Suppression for Electrical Systems Supplying Static Power Converters and Other Nonlinear Loads", IEEE Transactions on Industry Applications, VOL IA-15, No. 5, September/October 1979, pp 453-458.

[2] "IEEE Guide for Harmonic Control and Reactive Compensation of Static Power Converters", IEEE Standard 519, 1981.

[3] "Canadian Forces Technical Orders C-12-130-OFO MF-Z04 VOL 1, Electrical System, 1981.

[4] A. Fanthome, G. Kettleborough, "The Simulation of Aircraft Electrical Power Systems", Copyright by Simulation Councils, Inc., August 1980.

[6] Yao-nan Yu, Electric Power System Dynamics, Academic Press, 1983.

[7] B.R. Gungor, "Power Systems", Harcourt Brace Jovanovich, 1988.

[8] Aircraft Electric Power Characteristics, Military-Standard-740E, 1 May 1991. 